\title{
Correction to: Shear wave elastography characteristics of upper limb muscle in rigidity-dominant Parkinson's disease
}

\author{
Chang Wei Ding ${ }^{1} \cdot$ Xin Song $^{1} \cdot$ Xin Yu Fu ${ }^{1} \cdot$ Ying Chun Zhang ${ }^{1} \cdot$ Pan Mao ${ }^{1} \cdot$ Yu Jing Sheng ${ }^{1} \cdot$ Min Yang ${ }^{1} \cdot$ \\ Cai Shan Wang ${ }^{1} \cdot$ Ying Zhang ${ }^{1} \cdot$ Xiao Fang Chen ${ }^{1}$. Cheng Jie Mao ${ }^{2}$. Wei Feng Luo ${ }^{2}$. Chun Feng Liu ${ }^{2}$
}

Published online: 2 March 2021

(C) Fondazione Società Italiana di Neurologia 2021

Correction to: Neurological Sciences (2021) https://doi.org/10.1007/s10072-021-05088-3

The original article contains an error. In Affiliation 2, "Psychiatry" should be change to "Neurology". Author Affiliation should write as follows: ${ }^{2}$ Department of Neurology, The Second Affiliated Hospital of Soochow University, Suzhou, China.

The original article has been corrected.

Publisher's note Springer Nature remains neutral with regard to jurisdictional claims in published maps and institutional affiliations.

The online version of the original article can be found at https://doi.org/ 10.1007/s10072-021-05088-3

Ying Chun Zhang

richer777@126.com

1 Department of Ultrasound, The Second Affiliated Hospital of Soochow University, 1055 Sanxiang Road, Suzhou 215004, China

2 Department of Neurology, The Second Affiliated Hospital of Soochow University, Suzhou, China 